Archived version from NCDOCKS Institutional Repository http://libres.uncg.edu/ir/asu/

\title{
Appalachỉan
}

B O O N E, N O R T H C A R O L I N A

\section{Redefining Boundaries in Families through Social Networking Leisure}

\author{
Authors: Iryna Sharaievska \& Monika Stodolska
}

\begin{abstract}
The purpose of this study was to explore the influence the use of social networking sites (SNS) for leisure has on boundaries between families and the outside world, as well as boundaries between family members. The family systems theory and the concept of boundaries served as a basis for this study. Seven families (22 individual family members) took part in the study. Group and individual interviews were conducted for this study. The data supported previous research claiming that connection with the outside world was among the major reasons for using SNS. The findings also suggested that families tried to preserve clear boundaries between themselves and the outside world by controlling who can access their accounts, what information can be shared and what is appropriate time to use SNS. The findings also suggested that the boundaries between family members are constantly being redefined to meet the changing realities of technological world
\end{abstract}

Iryna Sharaievska \& Monika Stodolska(2013) "Redefining Boundaries in Families through Social Networking Leisure" Leisure Sciences 37(5), 431-446 Version of Record available at (www.tandfonline.com/toc/ulsc20/current) 


\title{
Redefining Boundaries in Families through Social Networking Leisure
}

\author{
IRYNA SHARAIEVSKA \\ Department of Recreation Management and Physical Education \\ Appalachian State University \\ Boone, NC, USA
}

MONIKA STODOLSKA

Department of Recreation, Sport and Tourism

University of Illinois at Urbana-Champaign

Champaign, IL, USA

\begin{abstract}
The purpose of this study was to explore the influence the use of social networking sites (SNS) for leisure has on boundaries between families and the outside world, as well as boundaries between family members. The family systems theory and the concept of boundaries served as a basis for this study. Seven families (22 individual family members) took part in the study. Group and individual interviews were conducted for this study. The data supported previous research claiming that connection with the outside world was among the major reasons for using SNS. The findings also suggested that families tried to preserve clear boundaries between themselves and the outside world by controlling who can access their accounts, what information can be shared and what is appropriate time to use SNS. The findings also suggested that the boundaries between family members are constantly being redefined to meet the changing realities of technological world.
\end{abstract}

Keywords Facebook, family boundaries, family leisure, social media, technology

\section{Introduction}

Social networking sites (SNS) such as Facebook, MySpace, Google+, and Twitter are a regular part of leisure and everyday life among people of various age groups, genders, and racial/ethnic backgrounds. In the last 10 years, social networking sites have become a mainstay of social relations in much of the world. There are currently around 1.28 billion monthly active users (MAUs) of Facebook worldwide, with the yearly increase of $15 \%$ (Facebook, 2014). The typical American Facebook user currently spends around 15 hours per month using this SNS (Statistic Brain, 2012). The rapidly progressing development of SNS has led to multiple issues that have been examined in previous research, including reverse power dynamics in families (Watkins, 2009), a decrease in time spent with family (Mesch, 2006), self-reported addiction to SNS (Watkins; Wilson, Fornasier, \& White,

Received 12 November 2013; accepted 18 February 2015.

Address correspondence to Iryna Sharaievska, Appalachian State University, Department of Recreation Management and Physical Education, 111 Rivers Street, HCC 051, Boone, NC 28608-2181. E-mail: sharaievskai@appstate.edu 
2010), and problems with privacy control and safety (Lenhart \& Madden, 2007; Stutzman, 2006).

The amount of leisure time Americans spend using SNS and previous findings regarding the issues associated with such use make it surprising that the influence of SNS technology on families' relationships and leisure has not attracted more attention from leisure researchers. Since the importance of family leisure for family functioning and family satisfaction has been well established (Agate, Zabriskie, Agate, \& Poff, 2009; Kelly, 1997; Shaw, 1997; Shaw \& Dawson, 2001), factors that may influence the amount and the quality of time families spend together deserve academic attention. Better understanding of technology-based family leisure and its influence on family relationships could help families adjust to the changes in the modern technological world. Moreover, this study could help family counselors understand some reasons for family conflicts related to technology use. Lastly, leisure professionals could obtain useful information on the ways technology can be used to develop shared family leisure activities.

One of the ways SNS might influence family relationship and leisure is by changing perception and permeability of family boundaries (Broderick, 1993). Boundaries are an important part of the Family Systems Theory (Broderick) because each family establishes boundaries to protect itself from undesirable outside influences. However, families also maintain connections with the outside world to obtain necessary resources and be successful. The theory also posits family members ensure positive relationships within the family by creating certain boundaries between each other. Considering the potential influence of technology-based leisure on both internal and external family boundaries, there is a need to explore this topic in more detail.

The goal of this study was to examine how the family system has been influenced by the use of SNS for leisure. Specifically, the objectives of the study were 1) to explore the influence of SNS on boundaries between the family and the outside world and 2) to explore the influence of SNS on boundaries between members within the family. Due to the high popularity of Facebook among teens ages 12-17 (Madden, 2013), this study focuses on families with teenage children. Although work-related use of technology might influence family leisure (Valcour \& Hunter, 2005), this project will focus mainly on the impact of leisure related social media use on family relationship.

\section{Theoretical Background}

The Family Systems Theory was employed as a theoretical framework for this study. According to White and Klein (2008), the Family Systems Theory posits:

(a) all parts of the system are interconnected; (b) in order to understand the system we have to study it as a whole; (c) system and environment are interconnected: system influences the environment and environment influences the system; (d) "system" is not a real thing but rather a way of knowing. (p. 156)

Based on these premises, family should be studied as a complex system that cannot be understood without taking into consideration a variety of its components interacting with each other. Moreover, as Lanigan (2009) argued, a family does not exist in a vacuum and thus cannot be examined without consideration of the social, geographic and economic environment in which it is immersed. According to the Sociotechnological Model introduced by Lanigan, family's interaction with technology is influenced by array of factors, such as individual traits of family members, technology features and characteristics, family 
structure and stage in lifecycle, and extra-familial influences-community, workplace, and marketplace.

Family Systems Theory comprises a concept of boundaries that exist between different family members, as well as between family members and society (Broderick, 1993). The success of families depends on how well they are bonding with the outside world (Broderick). The boundaries exist to manage the family's connection with such formal systems as work, school, marketplace, social work, health care, and others (Frone, Russell, \& Cooper, 1992; Grossman, 2006; McKie, Cunningham-Burley, \& McKendrick 2005; Phelan, Davidson, \& Cao, 1991; Serovich \& Greene, 1993; Valcour \& Hunter, 2005).

Broderick (1993) claimed these boundaries are selectively permeable and are created and regulated by each family member according to his or her values to ensure the territorial, temporal and material welfare of the family. The boundaries also exist to protect family's lifestyle, world view, privacy, and social placement. Families differ by the "degree of permeability" of their boundaries or how open or closed those boundaries are (White \& Klein, 2008, p. 158). This level of permeability is related to both physical and symbolic boundaries and defines how easily information and resources flow in and out of the family and how protective the family is of its privacy. This study will explore whether technology has an impact on the perception of those boundaries by family members.

Multiple factors influence how families see their family boundaries. In families of diverse structures such as divorced, cohabiting, step-families, or single-parent families, the boundaries become ambiguous and often have to be redefined (Brown \& Manning, 2009; Glenwick \& Mowrey, 1986; Madden-Derdich, Leonard, \& Christopher, 1999). As described by Boss and Greenberg (1984), family boundaries ambiguity is a state of the family when it is unclear who belongs to the family circle and who does not. The family boundaries ambiguity is also associated with the lack of clarity on what roles and responsibilities each family member has. Such ambiguity may be related to a loss of family member due to death, divorce, deployment, or illness and is typically associated with higher level of distress in family (Carroll, Olson, \& Buckmiller, 2007; Mu, Kuo, \& Chang, 2005; Peterson \& Christensen, 2002).

Boundaries also exist between different family members. Family members have to ensure the level of social interaction (or connectedness) and withdrawal (or separateness) is acceptable to everyone in the family (Broderick, 1993). If these patterns of behavior are not balanced, family members (spouses or parents and children) will most likely act dysfunctionally with the purpose to return to homeostasis or the state of relationship equilibrium, in process damaging relationship's intimacy (Broderick). This project will explore whether SNS use has an impact on perception of the boundaries by family members.

\section{Literature Review}

Introduction of social networking sites caused multiple debates about its impact on relationships in families and communities. Boyd and Ellison (2008) defined SNS as "web-based services that allow individuals to (1) construct a public or semi-public profile within a bounded system, (2) articulate a list of other users with whom they share a connection, and (3) view and traverse their list of connections and those made by others within the system" (p. 211). Multiple studies report mixed findings on whether and how SNS use influenced relationships in families. 


\section{Social Networking Leisure and Family's External Boundaries}

Christakis and Fowler's (2009) research shows that interaction in contemporary world has been changed by SNS in four ways: enormity (increase in number of people who can be reached), communality (scale on which information can be shared), specificity (more particularity in formed ties), and virtuality (ability to assume virtual identities). Along with increased number of connections allowed by use of SNS and other technology, those connections are also often meaningful. For example, a study by Hampton, Goulet, Rainie, and Purcell (2011) showed regular Facebook users (i.e., use Facebook several times a day) have more discussion confidants (people with whom they discuss important matters) and get more social support (including total, emotional support, and companionship) than nonusers. This study also showed Facebook helps to maintain close social ties and revive "dormant" relationships that currently are not active relationships but may become a source of information at some point (Hampton et al.). Similarly, Ellison, Steinfield, and Lampe's (2007) study showed SNS was helpful for initiation of friendships and development of bridging social capital among students. In relation to bonding social capital, the use of Facebook did not help to develop close relationships; however, it helped to support existing ones (Ellison et al.).

While the role of SNS in maintaining relationships separated by distance is often beneficial, multiple issues associated with SNS use were explored by previous research. Among these are decrease in commitment and shallowness of relationship (Turkle, 2011), cyber bullying (Pempek, Yermolayeva, \& Valvert, 2009), and issues related to privacy (COPPA, 2000). However, there is still very little known on how families perceive, establish and manage boundaries between their family and the outside world in contemporary digital environment.

\section{Social Networking Leisure and Family's Internal Boundaries}

Besides contacts with the community outside the family, the relationships between romantic partners or parents and children are also impacted by the use of SNS. Recent data show that two-thirds of parents of children age 12-17 use social networking sites, and $80 \%$ of them are Facebook friends with their children (Madden, Cortesi, Gasser, Lenhart, \& Duggan, 2012). Parents often initiate this connection due to their concern about their adolescent children's interaction with strangers, online reputation, and future career prospects (Madden et al., 2012). This concern is understandable considering the opportunity provided by SNS to make the boundaries of the family more permeable, access new information from outside of family, "try on" different identities, and explore their relation to peer group and community (Kim \& Lee, 2010; Pempek et al., 2009; Watkins, 2009). In response to this concern parents use SNS for parenting purposes (more often than other media such as messaging, Skype, chat rooms, or blogging) and interact with their children, their children's friends, and parents of their children's friends (Doty \& Dworkin, 2014).

The way parents and their adolescent children interact via SNS often is a reflection of their offline interaction. For example, in study by Burke, Adamic, and Marciniak (2013), mothers showed more affection and support, while fathers shared factual information with their children. Mothers were also the most social on Facebook and led conversation in most of the cases. The gender of children was also an influential factor in how parents expressed themselves on Facebook, with girls been treated more emotionally and boys been pushed toward independence (Burke et al.). Another factor influencing parent-child SNS interaction was children's age. Parents of younger teens were more controlling and protective of their children's exposure on SNS (Madden et al., 2012). Parents with older 
children were more likely to have neglectful or indulgent parenting styles and less likely to set limits on online behavior (Rosen, Cheever, \& Carrier, 2008). Lastly, child's personality characteristics and self-esteem level played role in their use of SNS (Wilson et al., 2010).

Due to novelty of SNS technology parents of teens only start defining their parental role related to SNS use by their children. Madden et al. (2012) described that parents helped their children to establish boundaries with outside world by using parental control, talking to children about online profiles, learning about and helping set up privacy settings, and searching for child's name online. Despite general belief that adolescents are against being friends with their parents on Facebook, the study by Kanter, Afifi, and Robbins (2012) showed that adolescents did not perceive being Facebook friends with their parent as violation of their privacy. Moreover, such Facebook friendship was associated with lower conflict and higher feeling of connectedness in parent-child dyads (Kanter et al.). Adolescent participants in another study claimed having very positive reactions (delighted, flattered, and calm) to their mother's friend request on Facebook (Karl \& Peluchette, 2011). Although children did not mind being Facebook friends with their parents, they believed they had to behave differently when they knew their parents could witness their behavior (Madden et al., 2012). Similarly, parents adjusted their behavior online when they talked to their children. In the attempt to fit in, they used more swear and slang words (Burke et al., 2013). It is not clear whether teens had a hard time dealing with freedom allowed by SNS and appreciated their parents help navigating interactions with the outside world, or parental monitoring was used as an opportunity to connect with parents in more familiar for youth way.

Starting to define norms and set boundaries for romantic partners using SNS, Gershon (2010) introduced the concept of digital ideologies. Digital ideology was defined as perception of what is appropriate way and media (e.g., email, personal Facebook message, Facebook wall post) to communicate specific message (i.e., invitation for a date, conflict or break up). It was suggested that certain media (email, text, or Facebook) and the way they are used communicates the message along with the actual wording of the message, often more powerful than words. The author explained that differences in media ideologies between partners may lead to confusion and disagreement. Examples of redefining boundaries between spouses include changing the mode of communication (from personal and family email account to work email account) and time of communication (from personal evening time to more formal work day time) following a divorce (Gershon).

Due to SNS novelty, our society is still developing social norms guiding use of these technologies in the context of family (Gershon, 2010; Kanter et al., 2012; Karl \& Peluchette, 2011; Madden et al., 2012). Lack of such norms and clarity on the technology use, amount of time spent using it at home, the rules about technology use and the role technology plays in family life may lead to conflict among family members (Huisman, Edwards, \& Catapano, 2012). As Subrahmanyam and Greenfield (2008) highlighted, research on parent-children perception of and interaction via SNS is in its infancy. There is little known how use of SNS influences perception and management of boundaries within family - between spouses and between parents and their children. As a result, the goal of this study is to examine how internal and external family boundaries are influenced by family members' use of SNS.

\section{Methods}

This study was based on the principles of constructionism and interpretivism, which suggest reality is "constructed in and out of interaction between human beings and their world" (Crotty, 1998, p. 42) by using socially constructed "system of significant symbols" 
(p. 54). This study was conducted in a medium-size town and a big city in the Midwest during fall 2011 and winter 2012. A purposive sampling technique was used to select participants who could provide information on the phenomena under study (Bernard, 2000). To recruit participants, information about the study was advertised through several list-servs (including one university and one middle school list-serv) and on several Facebook profiles. The data were collected from 22 individuals (7 families) using semi-structured individual and group interviews (29 interviews total). All seven families were two-parent families and had more than one child. Only children who were 13-17 years old participated in the study. One family had two children participating in the project. Two families identified themselves as working class, while the rest of the participants identified themselves as middle class. Four families were of Caucasian background, two families were Latino, and one family was interracial (South Asian-Caucasian). The participants were rewarded with a $\$ 30 \mathrm{gift}$ certificate per family.

Members of each family were interviewed on the same day. Each family was interviewed on a different day. Family interviews were followed by individual interviews with each family member. All interviews were conducted in English and lasted around 30 minutes. Based on the interviewees' preference, the interviews took place in either their residence or in a university laboratory. Among questions asked during family interviews were: "Describe the pattern of your use of SNS for leisure." "Are there any rules about by whom, when, and how SNS may be used?" During the individual interviews the participants were asked: "How do you think your use of SNS influences your family relationships?" "Are there any conflicts between the members of your family because of the SNS use?"

The interviews were audio-recorded and transcribed verbatim. Interview transcripts were analyzed using constant comparative method (Glaser \& Strauss, 1967). Pseudonyms were given to all participants. The data analysis followed several coding techniques: initial, focused, axial, and theoretical coding (Charmaz, 2006). Starting from initial coding the main patterns and contrasts were identified and initial codes created, including setting the boundaries and creating connections with extended family, co-workers, childhood friends, current friends, strangers, setting the boundaries and creating connections within the family. The extended family was considered to be a part of the external world since the pattern of interaction between nuclear and extended family was more similar to the pattern of interaction between family and people from outside world (updating about events rather than utilitarian role, main way of interaction rather than complimentary to in-person interaction). During focused coding stage, the most significant, frequent and conceptually sound categories were defined and used to sift through the data. Axial coding helped to further develop the categories and subcategories and define links between them. Lastly, during theoretical coding the relationships between categories were conceptualized in order to develop theory.

The trustworthiness of this study was evaluated based on four main criteria suggested by Charmaz (2006): credibility, originality, resonance, and usefulness. To ensure credibility, the researchers conducted the literature review and developed deep understanding of the topic. The amount of data was constantly monitored and analyzed to ensure the point of saturation was reached. The developed categories were discussed with an independent researcher in the field. As a result of this feedback, the section on boundaries between the members of the family was split into two subthemes-marital relationships and SNS, and parenting and SNS. Originality of this project can be noticed in a novel approach toward research on marital and family satisfaction in relation to technology-based leisure. While previously conducted projects explored marital and family satisfaction using quantitative approach, this study provides rich qualitative data. To ensure resonance, the member check was conducted. The interview transcripts were sent to interviewees whose contact information 
was available for verification and feedback. The study usefulness was insured by focusing on the timely issue and offering recommendations to professionals on how the results could be used.

\section{Findings}

The participants in the study discussed various ways they managed the boundaries within and outside their families. The data were classified into two major themes and several subthemes. The first theme, the boundaries between the family and the outside world, included subthemes such as staying connected to the outside world and setting boundaries on family connectedness. The second theme, the boundaries between the members of the family, included subthemes such as marital relationships and SNS, and parenting and SNS.

\section{Boundaries Between the Family and the Outside World}

Contemporary families use SNS technology to connect with the outside world. While in the past families maintained contact with the outside world to exchange resources, they rarely had an opportunity to stay connected to such a high degree. Modern technology allows people from the outside world to reach the family at almost any time and to stay connected for unlimited periods of time. However, families still maintain control over the boundaries between themselves and the outside world. The following excerpts provide examples of those processes.

Staying connected to the outside world. One of the primary reasons for using SNS mentioned by the participants was to connect with other people (e.g., extended family, friends, and acquaintances from the past). Family members used SNS to stay in touch and to organize off-line meetings and celebrations. Katherine (mother) claimed the biggest appeal she found in SNS was the ability to connect with their extended family living in a different country. She said, "I really like to use Facebook because I could find some friends from the past. [... ] He [husband] has an aunt and I thought that she died but she is alive" (group interview). Another participant, Melisa (mother), was happy to re-connect with people she has not seen for a long time. She said:

I am from India and I have a lot of friends that I lost touch with since I left India 20 years ago, until Facebook. They all trying to get on Facebook and it's been wonderful—all these people that I told stories about to my husband. (group interview)

These quotes, as well as quotes of other participants whose relatives lived abroad, illustrate that SNS helped them to stay connected with people they would not have chance to stay connected otherwise.

By using SNS family members did not only virtually stay in touch with the outside world but also planned their leisure time with others by finding tickets to plays, and planning sleepovers or birthday parties. For example, Sandra (mother) shared:

This year [ ... ] a lot of extended family got on it, so we hosted family reunion this summer and I did the whole thing through Facebook - the invitations, everything, set-up an event page and it was awesome! We had the best time! (individual interview) 
Children also organized sleepovers and birthday parties using their Facebook profiles. As Emily, a mother of a teenage boy, described, "For my son's birthday this year, things were very busy, so he organized a ping-pong party and he did it strictly through Facebook" (group interview). Connection to their peer group was also among most often reasons to use SNS mentioned by youth. As Erik (teenage boy) explained, "Sometimes it's just chat but sometimes I'll have something I wanna post or something I wanna check, you know some bit of information about an event... to check notifications sometimes to see if anything is coming up" (individual interview). Parents understood the importance of the social connections their children maintained through the social networking sites and tried to refrain from limiting how much time they can spend on it.

Setting boundaries on family connectedness. While staying connected with the outside world was among main reasons many interviewees used SNS, many participants felt the need to define and protect boundaries between their family and the outside world, as well as to create their own rules regarding the information flow across those boundaries. In every family, when SNS accounts were created by children, parents had conversations with them about privacy settings, content of pictures and posts, appropriate friendships and times and spaces for using SNS.

Control over privacy settings. Most participants reported that their SNS account settings were set to a high level of protection to ensure privacy from the outside world. For example, Oliver (father) stated, "We have a recovery question for my password and a really complicated password and I don't put a lot of personal information on it" (group interview). Several other participants decided not to use their real dates of birth, middle names, and addresses on Facebook. Parents also discussed with their children what information and pictures are appropriate to post. As Oliver (father) said, "We've certainly talked with both boys about 'don't put that on Facebook, [ . . . ] that's really bad idea"' (group interview). In families with younger children, parents used an additional layer of protection and made decisions about who can be friends with their children. Those parents also highlighted the power they had to control the boundaries between their family and the outside world. For example, when Sandra's son jokingly highlighted during group interview that he should unfriend his mom, she threatened to delete his account, and followed up with exclamation, "I can do anything! I am your mother!"

Control over time. Some families clearly defined boundaries between their family and the outside world by separating private and public time. When asked about rules related to use of SNS, many parents mentioned certain times they found to be inappropriate for using SNS such as dinner time, time spent in church, and late evenings, which are traditionally seen as family time. For example, teenage girl Anita shared, "They trust me but they just say they don't want me there [on Facebook] late at night because that's the time when I should be resting or sleeping. [ . . ] I agree with that because they have a point. Sometimes it's kind of annoying in summer time because I don't have to wake up early in the morning." She also provided example of conflict resulting from an attempt to push those boundaries:

For example, I would be on it [Facebook] and my mom is calling me to dinner and I'll be like 'ok, I'll be there.' But sometimes I'll be having a conversation so it will drag out, my mom will get mad at me, she will be like 'Ok, come, it's time to eat dinner, get off the Facebook and turn off your computer. Come.' (individual interview) 
A teenage boy, Dennis shared a similar story:

Usually they tell me in church "Put your phone away," "get off Facebook," or when we are eating.. I kind of know it, it's mostly implied that it's family time [ ... ]. I guess when I am bored I would use it. Like if there is nothing going on at the moment but it's still family time, I usually just pull it out [cellphone to use Facebook]. At church I'd be bored and I would take it out, they told me not to take it out. I just accepted it but what I've learned is that when they are not looking I would take it out. (individual interview)

It is important to highlight that since parents were the ones to establish rules, in some cases they established different level of boundary permeability for their children and for themselves. Several adolescent participants reported their parents to use SNS excessively (including during dinner and other traditionally family time) and posting too much of information about them and their family. One child even used word "addicted" describing his mother's use of Facebook.

Control over information. One of the ways to define boundaries between the family and the outside world is to maintain control over broadcasted information and image of their family presented to their friends and acquaintances. Melisa (mother) described how she created her family image on SNS: "Well, I think I do use Facebook as a turf of expression of things that are good about being a mom and being a wife and I post a lot of pictures of happy kids" (individual interview). Another mother (Sandra) also used Facebook to show her friends how proud she was of her children: "And I think that's one reason I am on it so much, like at her [daughter's] games and things like that . . 'cause I am posting, bragging 'ohh, she got a homerun!"' (individual interview). Other parents had more strict boundaries between their family and the outside world. For example, Olivia (mother) wanted to preserve the control she had over the family pictures her teenage daughter posted on Facebook. She said:

I told her a couple of times to be really careful and I also tell her to not put any pictures of me or your close family, because I don't want nobody to see me. Only if you really like the picture show it to me and we'll discuss that. I don't want anybody to talk about me or my family and I also tell my other daughter to be really careful with what kind of information you put on Facebook or pictures of my family, even their sisters. (individual interview)

Interestingly, participants had a general perception that others also carefully monitor the information posted on social networking sites, craft certain image of their families and set clear boundaries between private and public of their families and the outside world. As Melissa explained:

I think people always post their happiest moments and their most remarkable moments and if you look through anyone's postings you might think that their lives are always wonderful, they have those incredibly talented children and their spouses are the handsomest men in the world and their lives are just a bed of roses. [... ] You know, I would not say "I just had a fight with my husband" or "my dog made a mess on the carpet." So, it is important to realize that those things happen in everyone's lives but they don't get posted on Facebook. (individual interview) 
By maintaining control over privacy settings time of use and information posted on Facebook, families defined boundaries between their family and the outside world. While families differed in how permeable those boundaries were, they all agreed that such boundaries should exist.

\section{Boundaries between the Members of the Family}

The participants seemed to be able to find the balance between connectedness and separation between their families and the outside social environment. The boundaries within the family, however, were not always as clearly defined. Due to advances in communication technologies, family members had to redefine what appropriate flow of information is across boundaries between spouses and between parents and their children.

Marital relationships and SNS. The general attitude toward SNS and views of what information related to use of SNS can be shared between spouses varied. While only one of the husbands reported he had password to his spouse's SNS account, there was some confusion about how private their online activities were. Many participants shared some information from Facebook with their spouses. They discussed events in the lives of their relatives and friends and claimed that Facebook often served as a conversation starter. As Melisa (mother) described, "And when I see somebody's pictures . . . somebody's new child or something I bring my family over 'look, I used to know them in high school and they have a kid now" (group interview). Some spouses however, found it intrusive when their spouses looked at their Facebook accounts without invitation. For example, Ashley (mother) said, "I don't mind showing some things to him [her husband] on Facebook, but I don't like... I guess I think of it as infringement of my privacy when I am on it and he wants to read everything that's on it" (group interview).

Besides lack of clarity on what information should be shared between spouses, some participants felt general mistrust toward SNS and preferred their spouses to spend less time using those sites. For example, Kathrine explained that she could only use Facebook when her husband was asleep. She said:

Sometimes he is sleeping and he needs to go to the bathroom and computer is in the room next to the bathroom. If he sees me on computer he says 'Hey, don't waste your time! [ . . ] better come talk with me, I am alone'. He likes to have us [wife and children] close to him or next to him or helping him. (individual interview)

Another husband, Robert, reportedly made comments about his wife's time spent on Facebook. His wife, Ashley, explained that those comments upset her. "Sometimes I become defensive because when they are watching sports for several hours and I get back to the computer I don't see any difference. They are relaxing, this is how I take time to relax" (individual interview). The presented above quotes support Gershon's (2010) point about lack of clearly defined norms and boundaries associated with the use of SNS by family members.

Parenting and SNS. The participants reported that the boundaries between parents and their children related to the use of SNS also had to be redefined. In many cases parents were serving as guardians of their children's safety on SNS, which can be viewed as a natural extension of their guardianship role. Many parents preserved some level of control over privacy settings of their children's accounts, set expectations as to who can be friends with their children, and when and where SNS can be used. Moreover, some parents 
reported they had access to their children's SNS accounts or checked them on a regular basis.

One of the strategies used by parents was friending their adolescent children, which allowed them to see what information they made public and who their friends were. For example, Sandra (mother) described, "Well, when they started they weren't allowed to have any friends that I didn't have so I could see what's going on. And then, as they matured [... ] we loosened that restriction up" (group interview). Another mother, Ashley, was a Facebook friend with some of her sons' friends and talked to them without knowledge of her children. She explained, "Some of their [sons'] friends have friended me and I think they [sons] think it's weird. So if I talk with one of their friends online I won't say anything to them [sons] about it" (individual interview).

Despite being granted more freedom with age, teenage participants still had some restrictions on the content of their posts. Some parents said that they received an alert every time their children posted anything. Others reported that their children were allowed to use SNS only in public areas in the house and only until a certain time in the evening. Sandra (mother) provided an example, "He [son] can do it on his iPad and stuff and if I am up at 1 am and doing something on there and I'm like 'why did he just post? He is supposed to be asleep'. And I am like 'Go to bed"' (group interview).

In some cases parents could access SNS accounts of their children due to their technology expertise or password knowledge. Answering the question about the knowledge of passwords of other family members, Ostin (father) said, "Yes [I know my wife's and daughter's passwords], my son-I can't memorize his because he's got a long string of digits but I suppose if I needed to I could access that one as well" (individual interview). While Ostin did not check the SNS accounts of his family members, other parents did not consider it to be an issue. For example, one mother checked her son's account without his knowledge on a regular basis. She explained, "I can know more about his feelings or how he is working with his feelings and sometimes as his mom I can help him more" (individual interview).

Technological changes in recent years have led to changing perceptions of boundaries, both when it comes to interactions with the outside world and between family members. Despite some lack of clarity about internal boundaries between spouses and between parents and children, many participants reported to "work on a trust system" and have an agreement about the external boundaries of the family.

\section{Discussion/Conclusion}

The main objective of this study was to explore the influence of SNS on boundaries between the family and the outside world, and within the family. Following Family Systems Theory (White \& Klein, 2008), this project explored two main subsystems of the family-spouses and parents-children. While extended family is usually considered to be a part of the family system, for the purposes of this project extended family was treated as external to nuclear family. Such approach was used due to the focus on the pattern of online interaction between nuclear and extended family which was more similar to the pattern of interaction between family and the outside world (e.g., updating about events rather than utilitarian role, main way of interaction rather than complimentary to face-to-face interaction). The findings show family members stayed connected to the outside world while still setting limits on the type of private information shared with the outsiders, who has access to this information, and time appropriate for use of SNS. Besides the relationships with the outside world, the boundaries between family members (spouse-to-spouse and parents-to-children) were also influenced by the use of social networking sites. 
Motivating factors for individual's use of SNS discussed in previous research were involvement, self-expression, and interaction (Chung, Koo, \& Park, 2012). Similarly, the participants of this project considered SNS to be important vehicle for connecting with people separated by time and space. This technology allowed participants not only to maintain contact with relatives and friends who lived far away but also to reestablish connections with people they knew in the past. Moreover, similar to participants of Lenhart, Purcell, Smith, and Zickuhr's (2010) study, interviewees of this project reported they used SNS to maintain contact mostly with people they already knew and not to make new friendships. Moreover, unlike the results of previous research, SNS did not seem to harm those "real life" relationships by making interactions more sporadic and shallow (Turkle, 2011). This might be explained by the fact that families in this study used SNS as a tool to foster already established relationships by planning and organizing face-to-face leisure events.

Controlling the boundaries was not always an easy task for families since there are still no clearly defined norms in the society about SNS use (Gershon, 2010). Despite lack of such norms, each family felt the need to maintain control over their family boundaries. By carefully monitoring privacy settings, time when SNS were used and information posted on SNS, families separated public and private areas of family life discussed by Goffman (1973). Although broadcasting a certain image through leisure and SNS on individual level was discussed in previous research (Chung et al., 2012; Pempek et al., 2009), the participants of this study reported a new trend. SNS were used by our participants to create and broadcast the image of an entire family.

Public and private family behaviors carefully separated to ensure family's privacy and positive public image are much harder to distinguish in modern technological environment. Information and images that used to be protected and private now often end up online potentially available to much larger audience. In addition, Goffman (1973) discussed the common practice of excluding young children from conversations about private family matters. With access to SNS, young people may be exposed to and share the information that may be considered sensitive by their parents. In order to navigate new possibilities for interaction with the outside world offered by SNS, parents in this study helped their children to establish and maintain the boundaries. Families created their own media ideology related to use of SNS (Gershon, 2010). They perceived using SNS at specific times (dinners, late evenings) or places (private areas of the house, church) as inappropriate.

Permeability of the boundaries varied between families, and between members of the same family. For example, families with younger teens established very rigid boundaries, and were more controlling and protective of their children exposure on SNS (Madden et al., 2012). In families with more traditional values, which in this study also happened to be of Hispanic background, parents wanted to check family pictures posted on Facebook, and had access to their child's account. Gender seemed to play important role in how families used SNS. Similarly to the participants of previous studies, mothers in this study were more social on Facebook (Burke et al., 2013). Mothers were also the ones who created positive image of their family via SNS. Most of the parents (irrelevant of cultural background and gender) used strategies discussed by Madden et al. (2012), such as their parental control, talking to children about online profile, and help to set up privacy settings. It is important to highlight that while in the past youth have been the ones blamed for excessive use of social networking sites (Goodstein, 2007; Lenhart et al., 2010), some parents in this study were as involved in the SNS use as the young people. Parents (especially fathers) were still the ones who were more careful about protecting the personal information of their families. However, it was also parents (usually the mothers) and not the children who reported sharing pictures of family events via social media. 
As a result of this study, Sociotechnological Model introduced by Lanigan (2009) and based on Family Systems Theory could be expended by adding a concept of internal and external family boundaries. Sociotechnological Model explains family as technology interaction as an interplay of factors. Among these factors are individual traits of family members, technology characteristics, family factors, and various extrafamilial influences, including community, workplace, and marketplace (Lanigan). Among family factors discussed by Lanigan are demographics and composition, stage of development, member use of technology, locale, and family processes. Family's view on permeability of family boundaries could be considered as one the factors affecting the pattern of interaction with technology and the outside world. Lanigan also discussed individual traits of family members as a factor in such interaction, including one's personality, goals, attitude, processing styles, and demographics. The individual's digital ideology could be added to this group of factors as well. Further exploration of informational flow from and to family, as well as between family members would be needed to provide more details on how social, geographic and economic environment of family impacts internal and external family boundaries associated with use of SNS.

Although this study has introduced several important issues that add to the literature on family leisure and the use of technology, it also had several limitations. First, the short period of time for interaction with each family could influence the researcher-participant rapport. Second, while this study is focused on family boundaries in the context of SNS by family members, the original goal of the project was to explore a broader topic, that is, relationships in family and use of SNS. While that might be considered as a study limitation, qualitative data are often analyzed by looking for similar patterns rather than exact wording. Third, all families participating in this study were two-parent families with adolescent children. Considering that families of different structure or in different life stage (single-parent families, those who share household with their grandparents, those with small children) might have different amount of time available for family leisure, the findings of this study might not always be transferable to their specific situations.

Considering the multiplicity of influences SNS has on relationships and boundaries in contemporary families, it is important to further explore several issues introduced in this study. The differences in the perceptions of privacy, media ideologies, and general attitude toward SNS in contemporary families should be explored in more detail. Moreover, it would be beneficial to examine what kind of families (on a spectrum between happy and families in distress) are more willing to share information in the online environments and what roles do SNS technologies play in the process of coping among members of families in distress. While comparing different types of families, it would be important to examine whether their online and offline boundaries vary on the level of flexibility and openness.

For professional counselors who work with families, it would be important to explore issues related to SNS use. As participants suggested, the disagreements about media ideologies and permeability of family boundaries are among issues that can lead to conflict between family members. At the same time, however, SNS can be used by families for joint, satisfying leisure pursuits that build connection and trust among family members. For example, recreational organizations offering family programs and events could provide families with opportunities to co-organize those events by using SNS as a platform for brainstorming, planning, and administration. Moreover, family ties might be strengthened and communication might be improved thanks to use of SNS for creating shared leisure experiences with members of both immediate and extended families. Lastly, some clarification of boundaries and reaching agreement on media ideologies between spouses could help eliminate some disagreements and conflict. 


\section{References}

Agate, J. R., Zabriskie, R. B., Agate, S. T., \& Poff, R. (2009). Family leisure satisfaction and satisfaction with family life. Journal of Leisure Research, 41(2), 205-223.

Bernard, H. R. (2000). Social research methods: Qualitative and quantitative approaches. London, England: Sage.

Boss, P., \& Greenberg, J. (1984). Family boundary ambiguity: A new variable in family stress theory. Family Process, 23(4), 535-546.

Boyd, d. m., \& Ellison, N. B. (2008). Social network sites: Definition, history, and scholarship. Journal of Computer-Mediated Communication, 13, 210-230.

Broderick, C. B. (1993). Understanding family process: Basics of family systems theory. Thousand Oaks, CA: Sage.

Brown, S. L., \& Manning, W. D. (2009). Family boundary ambiguity and the measurement of family structure: The significance of cohabitation. Demography, 46(1), 85-101.

Burke, M., Adamic, L. A., \& Marciniak, K. (2013). Families on Facebook. Association for the Advancement of Artificial Intelligence. Retrieved from http://www.aaai.org/ocs/index.php/ ICWSM/ICWSM13/paper/viewFile/5992/6342

Carroll, J. S., Olson, C. D., \& Buckmiller, N. (2007). Family boundary ambiguity: A 30-year review of theory, research, and measurement. Family Relations, 56(2), 210-230.

Charmaz, K. (2006). Constructing grounded theory: A practical guide through qualitative analysis. London, England: Sage.

Christakis, N. A., \& Fowler, J. H. (2009). Connected: The surprising power of our social networks and how they shape our lives. New York, NY: Little Brown and Company.

Chung, N., Koo, C., \& Park, S.-B. (2012). Why people share information in social network sites? Integrating with uses and gratification and social identity theory. Berlin, Germany: ACIIDS, Springer-Verlag Berlin Heidelberg.

COPPA - Children's Online Privacy Protection Act. (2000). Retrieved from http://www.coppa.org/ comply.htm

Crotty, M. (1998). The foundations of social research: Meaning and perspective in the research process. London, England: Sage.

Doty, J., \& Dworkin, J. (2014). Parents' of adolescents use of social networking sites. Computers in Human Behavior, 33, 349-355.

Ellison, N. B., Steinfield, C., \& Lampe, C. (2007). The benefits of Facebook "friends:" Social capital and college students' use of online social network sites. Journal of Computer-Mediated Communication, 12, 1143-1168.

Facebook investor relations. (2014, March). Facebook statistics. Retrieved from http://investor.fb. com/releasedetail.cfm?ReleaseID $=842071$

Frone, M. R., Russell, M., \& Cooper, M. L. (1992). Antecedents and outcomes of work-family conflict: Testing a model of the work-family interface. Journal of Applied Psychology, 77(1), 65 .

Gershon, I. (2010). The breakup 2.0: Disconnecting over new media. Ithaca, NY: Cornell University Press.

Glaser, B. G., \& Strauss, A. L. (1967). The discovery of grounded theory. Chicago, IL: Aldine Publishing.

Goffman, E. (1973). The presentation of self in everyday life. New York, NY: The Overlook Press.

Glenwick, D. S., \& Mowrey, J. D. (1986). When parent becomes peer: Loss of intergenerational boundaries in single parent families. Family Relations, 35(1), 57-62.

Goodstein, A. (2007). Totally wired: What teens and tweens are really doing online. New York, NY: St. Martin's Griffin.

Grossman, J. L. (2006). Family boundaries: Third-party rights and obligations with respect to children. Family Law Quarterly, 40(1), 1-6.

Hampton, K., Goulet, L. S., Rainie, L., \& Purcell, K. (2011). Social networking sites and our lives. Pew Research Internet Project. Retrieved from http://www.pewinternet.org/2011/06/16/ social-networking-sites-and-our-lives/ 
Huisman, S., Edwards, A., \& Catapano, S. (2012). The impact of technology on families. International Journal of Education and Psychology in the Community, 2(1), 44-62.

Kanter, M., Afifi, T., \& Robbins, S. (2012). The impact of parents "friending" their young adult child on Facebook on perceptions of parental privacy invasions and parent-child relationship quality. Journal of Communication, 62(5), 900-917.

Karl, K. A., \& Peluchette, J. V. (2011). "Friending" professors, parents, and bosses: A Facebook conundrum. Journal of Education for Business, 86, 214-222.

Kelly, J. R. (1997). Changing issues in leisure-family research. Journal of Leisure Research, 29(1), 132-134.

Kim, J., \& Lee, J. E. R. (2010). The Facebook paths to happiness: Effects of the number of Facebook friends and self-presentation on subjective well-being. Cyberpsychology, Behavior, and Social Networking, 14(6), 359-364.

Lanigan, J. D. (2009). A socio-technological framework for family research and intervention: How information and communication technologies affect family life. Marriage and Family Review, 45, 587-609.

Lenhart, A., \& Madden, M. (2007). How teens manage their online identities and personal information in the age of MySpace. Pew Internet \& American Life Project. Retrieved from http://www.pewtrusts.org/uploadedFiles/wwwpewtrustsorg/Reports/Society and the_Internet/PIP_Teens Privacy SNS Report Final.pdf

Lenhart, A., Purcell, K., Smith, A., \& Zickuhr, K. (2010). Social media \& mobile internet use among teens and young adults. Pew Internet \& American Life Project. Retrieved from http: //pewresearch.org/pubs/1484/social-media-mobile-internet-use-teens-millennials-fewer-blog

Madden, M., (2013). Teens haven't abandoned Facebook (yet). Pew Internet \& American Life Project. Retrieved from http://www.pewinternet.org/2013/08/15/teens-havent-abandoned-facebook-yet/

Madden, M., Cortesi, S., Gasser, U., Lenhart, A., \& Duggan, M. (2012). Parents, teens, and online privacy. Pew Internet \& American Life Project. Retrieved from http://www.pewinternet.org/ 2012/11/20/parents-teens-and-online-privacy/

Madden-Derdich, D. A., Leonard, S. A., \& Christopher, F. S. (1999). Boundary ambiguity and coparental conflict after divorce: An empirical test of a family systems model of the divorce process. Journal of Marriage and the Family, 588-598.

McKie, L., Cunningham-Burley, S., \& McKendrick, J. (2005). Families and relationships: Boundaries and bridges. Families in Society: Boundaries and Relationships, 3-18.

Mesch, G. S. (2006). Family relations and the Internet: Exploring a family boundaries approach. The Journal of Family Communication, 6(2), 119-138.

Mu, P. F., Kuo, H. C., \& Chang, K. P. (2005). Boundary ambiguity, coping patterns and depression in mothers caring for children with epilepsy in Taiwan. International Journal of Nursing Studies, 42(3), 273-282.

Phelan, P., Davidson, A. L., \& Cao, H. T. (1991). Students' multiple worlds: Negotiating the boundaries of family, peer, and school cultures. Anthropology \& Education Quarterly, 22(3), 224-250.

Pempek, T. A., Yermolayeva, Y. A., \& Calvert, S. L. (2009). College students' social networking experiences of Facebook. Journal of Applied Developmental Psychology, 30, 227-238.

Peterson, D. J., \& Christensen, D. H. (2002). Factors predictive of boundary ambiguity after divorce. Journal of Divorce \& Remarriage, 37(3-4), 19-40.

Rosen, L. D., Cheever, N. A., \& Carrier, L. M. (2008). The association of parenting style and child age with parental limit setting and adolescent MySpace behavior. Journal of Applied Developmental Psychology, 29, 459-471.

Serovich, J. M., \& Greene, K. (1993). Perceptions of family boundaries: The case of disclosure of HIV testing information. Family Relations, 193-197.

Shaw, S. M. (1997). Controversies and contradictions in family leisure: An analysis of conflicting paradigms. Journal of Leisure Research, 29(1), 98-112.

Shaw, S. M., \& Dawson, D. (2001). Purposive leisure: Examining parental discourses on family activities. Leisure Sciences, 23, 217-231.

Statistic Brain. (2012). Retrieved from http://www.statisticbrain.com/social-networking-statistics/ 
Stutzman, F. (2006). An evaluation of identity-sharing behavior in social network communities. International Digital and Media Arts Journal. Retrieved from http://fredstutzman.com.s3. amazonaws.com/papers/IDMA2006 Stutzman.pdf

Subrahmanyam, K., \& Greenfield, P. M. (2008). Virtual worlds in development: Implications of social networking sites. Journal of Applied Developmental Psychology, 29, 417-419.

Turkle, S. (2011). Alone together: Why we expect more from technology and less from each other. New York, NY: Basic Books.

Valcour, P. M., \& Hunter, L. W. (2005). Technology, organizations, and work-life integration. In E. E. Kossek \& S. J. Lambert (Eds.), Managing work-life integration in organizations: Future directions for research and practice (pp. 61-84). Mahwah, NJ: Erlbaum.

Watkins, S. C. (2009). The young and the digital: What the migration to social-network sites, games, and anytime, anywhere media means for our future. Boston, MA: Beacon Press.

White, J. M., \& Klein, D. M. (2008). Family theories (3rd ed.). Los Angeles, CA: Sage.

Wilson, K., Fornasier, S., \& White, K.M. (2010). Psychological predictors of young adults' use of social networking sites. Cyberpsychology, Behavior, and Social Networking, 13(2), 173-177. 